\title{
Brasil: impactos do Covid-19 e recuperação*
}

\author{
Brazil: impacts of Covid-19 and recovery
}

\author{
Luiz Carlos Bresser-Pereira**
}

\begin{abstract}
Resumo: Este artigo examina os impactos do Covid-19 sobre a população e a economia brasileira, a elevada mortalidade por 100 mil habitantes e a lenta estabilização. E faz uma breve comparação com o que vem ocorrendo em um país semelhante da América Latina, onde os resultados em termos de mortes por 100 mil habitantes foram melhores, e na França, onde a recuperação foi mais forte. $\mathrm{O}$ trabalho avalia também a eficiência nos gastos; a comparação também não foi favorável ao Brasil. Finalmente, discute o problema do financiamento, argumentando que apenas a Argentina valeu-se da política adotada pela maioria dos países ricos que têm moeda e banco central próprios (não é o caso da França) de compra pelo banco central do país de títulos emitidos pelo tesouro.
\end{abstract}

Palavras-chave: Covid-19; Nação; Crescimento; Despesas; Financiamento

\begin{abstract}
This article examines the impacts of Covid-19 on the population and the Brazilian economy, the high mortality per 100 thousand inhabitants and the slow stabilization. And it makes a brief comparison with what has been happening in a similar country in Latin America, where the results in terms of deaths per 100 thousand inhabitants were better, and with France, where the recovery was stronger. The paper also analyzes the expenditure efficiency; the comparison was also not favorable to Brazil. Finally, it discusses the problem of financing, arguing that only Argentina has used the policy adopted by rich countries that have their own currency and central bank (not the case of France) of purchase by its central bank of treasure's bonds.
\end{abstract}

Keywords: Covid-19; Nation; Growth; Expenditure; Financing

JEL: I18; O29; E5

\footnotetext{
* Submissão: 12/11/2020 | Aprovação: 02/02/2021 | DOI: 10.5380/re.v42i77.79358

** Professor emérito da Fundação Getúlio Vargas | E-mail: luiz.bresser@fgv.br | Página: www.bresserpereira.org.br | ORCID: 0000-0001-8679-0557 | Agradeço ao Tiago Porto, doutorando da EAESP/FGV, pela excelente assessoria que me prestou enquanto escrevia este artigo.
}

(i) \& Esta publicação está licenciada sob os termos de

Creative Commons Atribuição-Não Comercial 4.0 Internacional 


\section{Introdução}

Entre os anos 1930 e 1980 o Brasil cresceu de maneira satisfatória e se industrializou, no quadro de um regime de política econômica desenvolvimentista, mas, nos anos 1970, se endividou equivocadamente, e na década seguinte foi atingido pela grande crise da dívida externa à qual se somou uma alta inflação inercial. Fragilizado pela crise e sob pressão do Norte, que em 1980 fizera sua virada para o liberalismo econômico, o Brasil, entre 1990 e 1992, fez a abertura comercial e financeira, entrou em um processo de desindustrialização prematura, e voltou a ser um mero exportador de commodities, e, desde então, experimenta um processo de quase-estagnação que só foi interrompido por um período, nos anos 2000, devido a um boom de commodities. Entre 1950 e 1980, no quadro de um nacionalismo desenvolvimentista, a renda por habitante cresceu à elevada taxa de 3,5\% ao ano; desde 1980 cresce a 0,8\% ao ano, enquanto nesse mesmo período os países ricos crescem a 1,5\% ao ano e os países em desenvolvimento, 3,0\% ao ano. Em 2014 o país entrou em profunda recessão, seguida por uma recuperação muito insatisfatória que confirmou o quadro geral de quase-estagnação.

Foi nesse quadro econômico que o país, como todos os demais estadosnação, enfrentou a pandemia do Covid-19 no início de 2020. Alguns deles enfrentaram melhor do que outros. Melhor ou pior em termos de número de mortes, de desemprego, de aumento da pobreza, de queda do PIB, e de endividamento público. É difícil hierarquizar os países de acordo com esses cinco critérios de êxito ou de fracasso, mas é possível afirmar com alguma segurança que os resultados do Brasil e dos Estados Unidos foram piores do que os da China e da Nova Zelândia. Por outro lado, sabemos que os resultados alcançados foram tanto melhores quanto mais rapidamente cada país enfrentou o problema, quanto mais efetivos foram os isolamentos e o afastamento social, quantos mais testes e rastreamento dos infectados ou suspeitos de infectados foram feitos, quanto mais forte e correta foi a orientação do governo à população em relação a essas medidas, quanto mais os habitantes de cada país se solidarizaram diante da pandemia e cooperaram com o governo na adoção dos comportamentos voltados para diminuir a difusão da doença, quanto melhor já era o sistema público de saúde, quanto mais apoio orçamentário teve ele quando irrompeu a pandemia, quanto mais e melhor o Estado gastou para assim diminuir o número de mortes, para limitar o aumento do desemprego e a quebra das empresas e a redução da demanda, e, finalmente, qual foi a forma pela qual as despesas de emergência foram financiadas, se por 
endividamento do Estado junto ao setor privado e aumento da dívida pública, ou por financiamento monetário - a compra pelo Banco Central de títulos emitidos pelo Tesouro às despesas associadas com a pandemia.

Neste ensaio discutirei o caso do Brasil. Discutirei seus maus resultados no enfrentamento da pandemia. Haverá alguma relação entre o baixo crescimento da economia brasileira desde 1980 e o elevadíssimo número de mortes pelo Covid-19? Não é possível afirmar com segurança que essa relação existe. Mas uma coisa me parece certa: para que um estado-nação seja capaz de se desenvolver e de enfrentar os novos problemas que estão sempre surgindo é preciso que ele conte com uma nação coesa. Ora, a coesão da nação brasileira, que havia aumentado fortemente nos anos 1980 com a construção de uma coalizão de classes popular-democrática e a aprovação de uma constituição social e desenvolvimentista, não logrou fazer o país a retomar o crescimento interrompido em 1980. E a partir das grandes manifestações populares de junho de 2013 ficou claro que essa coesão se tornara uma coisa do passado. Neste artigo, para avaliar se o Brasil realmente falhou em enfrentar o Covid-19, eu farei uma breve comparação com a Argentina e a França.

\section{Políticas públicas}

As políticas públicas adotadas pelos países para enfrentar a pandemia foram de três naturezas: (a) política sanitária visando diminuir o número de infectados e o número de mortes, (b) política fiscal visando garantir uma renda mínima para a população, reduzir o desemprego, a quebra das empresas e a queda do PIB causados pelas medidas sanitárias, e (c) política financeira visando financiar essas despesas associadas ao Covid-19.

A política sanitária que os infectologistas e as instituições internacionais voltadas para a saúde recomendaram e se revelaram bem sucedidas foram o fechamento das fronteiras do país, proibição de entrada de voos internacionais, fechamento de cidades ou regiões atingidas, adoção de testes em massa, rastreamento dos contatos das pessoas com teste positivo e seu isolamento, obrigatoriedade do uso de máscaras, criação de hospitais ou leitos de emergência, respiradores em quantidade suficiente, testes grátis, tratamento de saúde grátis, orientação da população sobre os comportamentos individuais, proibição ou forte restrição a demissões. Foram essas as medidas que tomaram dois países muito bem 
sucedidos no enfrentamento da pandemia, um país muito grande, a China, e um país muito pequeno, a Nova Zelândia.

A política fiscal adequada foi a de se expandir fortemente as despesas públicas ficando a preocupação com o forte aumento do déficit público em segundo plano; foi aumentar o gasto público (a) na área da saúde, aumentando o número de leitos nos hospitais e a disponibilidade dos equipamentos e drogas indicadas para enfrentar a doença; (b) em ampliação do auxílio-desemprego; (c) em uma política de renda básica para os mais pobres, (d) em uma política de estímulo às empresas para não demitirem empregados; (e) em diversas políticas de apoio às empresas para evitar sua quebra. E, mais amplamente, foi adotar uma política contracíclica de expansão do investimento público. Na área econômica, foram estas as políticas que os países que enfrentaram mais competentemente a pandemia adotaram.

\section{Critérios e políticas}

Para essa comparação escolhi dois países, a Argentina, porque é um país de renda média como o Brasil, que, não obstante os graves problemas que enfrenta, logrou evitar um grande número de mortes, e a França, porque julguei interessante ter um país rico para comparar. Escolhi como critérios de sucesso ou fracasso no enfrentamento do Covid-19 um número limitado de indicadores: o número de mortes por cem mil habitantes, o aumento da taxa de desemprego, o aumento da pobreza ou da desigualdade, a taxa de diminuição do PIB, o valor do gasto realizado mais a perda de receita do Estado. Os dados que consegui estão na Tabela 1; não são inteiramente comparáveis, mas nos dão uma boa ideia do desempenho do país. 
Tabela 1 - O Covid-19 no Brasil, Argentina e País Rico

\begin{tabular}{lccc}
\hline & Brasil & Argentina & França \\
\hline Mortes por 100 mil habitantes [1]* & 52,3 & 14,2 & 46,5 \\
Aumento Taxa de Desemprego (pontos percentuais) [2] & 2.3 & $1.5^{* *}$ & -0.5 \\
Aumento da pobreza ou da desigualdade 2020 [3] & $-0,9 \%$ & $11,5 \%$ & $0,0 \%$ \\
Taxa de diminuição do PIB 2020 [4] & $-9,1 \%$ & $-9,9$ & $-12,5$ \\
Gasto mais perda de receita \% PIB [5] & $11,8^{* * *}$ & 6,7 & 6,9 \\
\hline
\end{tabular}

Fontes: Dados referentes aos dois primeiros trimestres de 2020, a menos que indicado de outra forma. [1] WHO COVID 19 (Global Data: https://covid19. who.int/), e Worldometer para dados populacionais: www.Worldometers.info) [2] Brasil, Taxa de Desocupação da PNAD contínua; Instituição Fiscal Independent, Relatório de Acompanhamento Fiscal, https://bit.ly/3dpQSzT. Argentina, INDEC: https://www.indec.gob.ar)/uploads/ informesdeprensa/mercado_trabajo _eph_1trim20AF03C1677F.pdf). França, OCDE (https://data.oecd.org/unemp/unemploymentrate.htm) [3] Poverty headcount ratio at \$3.20/day (\%), a partir do Sustainable Development Report (2019 e 2020) : https://dashboards.sdgindex.org/explorer [4] Projeção WEO, Julho FMI: https://www.imf.org/en/Publications/WEO/Issues/2020/06/24/ WEOUpdateJune2020 [5] Brasil: https://www.imf.org/en/Topics /imf-and-covid19/Policy-Responses-to-COVID-19 Argentina e França, FMI mais nossa estimativa de redução da receita: https://www.imf.org/en/Topics/imfand-covid19/Policy-Responses-to-COVID-19.

Observações: *Mesmo número de dias para os três países (157 dias após a primeira morte).**Variação da taxa de desemprego entre o quarto trimestre de 2019 e o primeiro trimestre de 2020.***Segundo a Instituição Fiscal Independente (idem), a execução pelo governo federal das despesas e créditos liberados foi de 50,6\%.

\section{Número de mortes por 100 mil habitantes}

O resultado mais importante é, naturalmente, o número de mortes por 100 mil habitantes. De acordo com as estatísticas oficiais que utilizamos, o número de mortes no Brasil foi maior do que na França e muito maior do que na Argentina. Esse número, porém, está certamente subestimado. O epidemiologista da Universidade de São Paulo, Paulo Lotufo, afirmou que as mortes estão sendo subestimadas em todos os países. Por exemplo, segundo o New England Journal of Medicine, enquanto se estima que na Itália o número de mortes causadas pelo Covid-19 foi 30\% maior do que o apurado, em São Paulo, o mais populoso e mais rico estado do Brasil, ele estimou esse número em 170\%. ${ }^{1}$ Cálculos do Imperial College realizados em junho de 2020 estimaram que as mortes pelo vírus devem estar sendo três vezes maiores do que as que constam das estatísticas. ${ }^{2}$

\footnotetext{
${ }^{1}$ Ruprecht (2020).

${ }^{2}$ Sousa Pinto (2020).
} 


\section{Gráfico 1 - Novas mortes por 1 milhão de habitantes: Média móvel de 7 dias, a partir do primeiro caso de morte}

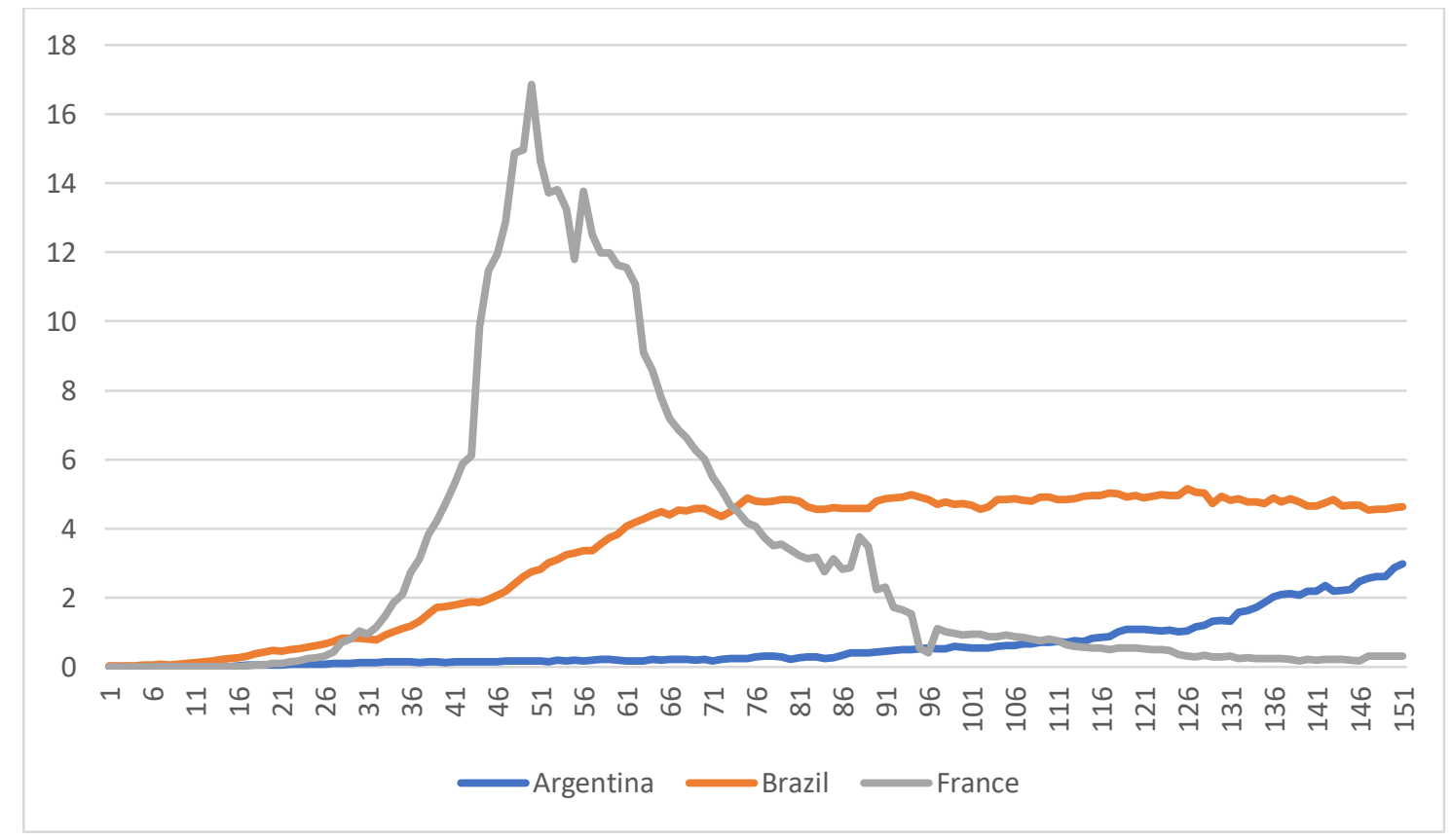

Fonte: World Health Organization. https://covid19.who.int/.

O número de mortes pelo Covid-19 foi certamente tanto menor quanto maior foi a firmeza dos governos em determinar os lockdowns e quarentenas, quanto maior foi o número de testes realizados, quanto melhor foi o rastreamento dos infectados, e quanto melhor foi a assistência médica e hospitalar. Mas, além disso, foi também crucial a variável tempo entre o primeiro caso de contaminação verificado no país e o início da política de contenção da doença. Quanto menor foi o número de dias entre os dois fatos, menor foi a difusão inicial da doença e menor, naturalmente, o número de infectados. O número de mortes na Argentina foi muito menor do que na França porque o governo argentino reagiu mais depressa do que o francês. Conforme observou José Natanson, não obstante as preocupações que governadores das províncias e prefeitos manifestaram com relação às consequências sociais de um fechamento forte e firme, o presidente Alberto Fernández agiu rapidamente e escolheu o caminho aparentemente menos popular da adoção de um forte sistema de isolamento e quarentenas. ${ }^{3} \mathrm{Na}$ França, como nos principais países da Europa, houve uma demora maior, que pode ser explicada pelo fato de que foram atingidos pelo coronavírus mais cedo do que no Brasil e na Argentina. Mas, assim que o governo francês tomou as providências

\footnotetext{
${ }^{3}$ Natanson (2020).
} 
necessárias, ele o fez de maneira competente, e o número de mortes caiu. Muito diferente foi o caso do Brasil. Conforme o mesmo epidemiologista já citado, Paulo Lotufo, "o Brasil poderia ter tido um terço das mortes e metade dos casos do novo coronavírus caso o distanciamento social tivesse sido adotado de maneira mais efetiva desde o início...."4.

No Gráfico 1 temos o número de mortes diárias causadas pelo Covid-19 a partir do primeiro caso de morte em cada país. Temos 151 dias porque foi esse o número de dias desde o início da pandemia na Argentina, o último dos três países a ser atingido. Vemos pelo gráfico que o melhor desempenho foi o da Argentina, e que, neste caso, foi crucial a rapidez do governo em agir. A França, como muitos países em que o Covid-19 se manifestou cedo, demorou para começar a agir e a doença se difundiu, mas em seguida passou a adotar com firmeza as políticas necessárias e o número de mortes caiu fortemente. Já o Brasil falhou completamente e o número de mortes, depois de crescer e chegar a um pico 75 dias após a primeira morte, não foi capaz de adotar as políticas que fariam a curva cair como caiu na França.

O governo federal, a quem cabia a responsabilidade principal da política a ser executada, não se atrasou em iniciar a combater o vírus, porque simplesmente não fez praticamente nada a não ser dificultar que o Sistema Universal de Saúde brasileiro (SUS) e os governadores e prefeitos agissem. Só começou a existir no Brasil uma política de contenção da pandemia quando servidores públicos associados ao SUS e os governadores dos estados e os prefeitos decidiram por conta própria iniciar a política de lockdowns. Sob crítica do presidente, que não parava de dizer que o problema não era grave, que não fazia sentido parar as empresas e as escolas, que bastava suprir os hospitais e ambulatórios públicos de duas drogas usadas para a malária - a cloroquina e a hidroxicloroquina - que até hoje não tem eficiência contra o Covid-19 reconhecida, mas tem contraindicações significativas. Os estudos até hoje realizados mostram que o medicamento não funciona mesmo quando aplicado na fase inicial da doença como o Ministério da Saúde passou a recomendar por orientação do presidente. Ministério esse que, em um quadro dramático como é o da pandemia, já trocou de ministro três vezes, e quando escrevo este artigo (início de setembro) é dirigido por um "ministro

\footnotetext{
4 Ver Paulo Lotufo, entrevista para a UOL, disponível em https://noticias.uol.com.br/saude/ultimasnoticias/redacao/2020/05/29/entrevista-paulo-lotufo-professor-de-epidemiologia-da-usp.htm?cmpid=copiaecola
} 
interino", o general Eduardo Pazuello, que não é médico, nem teve na sua carreira qualquer relação mais próxima com as políticas de saúde. Quanto aos governadores e prefeitos, agiram de maneira basicamente correta, mas sem o apoio que precisavam do governo federal. Houve, no começo da pandemia, um conflito aberto entre os principais governadores e o presidente, mas depois de menos de dois meses alguns dos governadores, particularmente o de São Paulo, que estava realizando uma política de lockdown bem feita, sofreu pressão dos empresários do comércio e dos restaurantes, e afrouxou a política.

\section{Custo da política sanitária e de proteção econômica}

Quanto gastaram os três países para enfrentar o coronavírus, reduzir o número de mortes, evitar a fome dos mais pobres, limitar o aumento do desemprego, e reduzir a quebra de empresas? E quanto caiu sua receita tributária devido à política de lockdowns e quarentenas? Somando-se esse aumento de despesa e diminuição de receita, quanto foi o "investimento" dos países para minorar os efeitos do Covid-19? Vemos pela Tabela 1 que surpreendentemente no Brasil, onde o governo federal não teve uma política de contenção da doença e de apoio às pessoas e às empresas, o gasto foi maior, 11,8\% contra 6,7\% na Argentina e 6,9\% na França. Mas há uma explicação simples. Um mês depois do início da pandemia o governo propôs um "auxílio emergencial" mensal, a partir de abril, de $\mathrm{R} \$ 200,00$ para os trabalhadores informais, microempreendedores individuais, autônomos e desempregados; mas o Congresso desprezou a proposta e a multiplicou por três, sem que estivesse claro, tanto para o Ministério da Economia quanto para o Congresso, quantos seriam os beneficiados - que afinal foram aproximadamente 60 milhões de pessoas. O auxílio nesse valor durou de abril a agosto. A partir de setembro, até dezembro, o valor do auxílio foi reduzido para a metade. Até dezembro o gasto total deverá ser de $\mathrm{R} \$ 450$ bilhões, representando cerca de $7 \%$ do PIB.

Quão eficiente foi esse gasto? Não é possível apresentar uma medida de eficiência única para cada país, porque os resultados não estão relacionados apenas a queda do PIB, mas também ao número de mortes, aumento do desemprego e aumento da desigualdade. Não é difícil, porém, concluir que o gasto no Brasil foi altamente ineficiente. Foi o país que gastou mais, e, no entanto, foi também o país com maior número de mortes por 100 mil habitantes e com maior aumento do 
desemprego. Apresentou, naturalmente, um desempenho melhor em relação ao item pobreza, mas a explicação deste fato foi a dimensão do auxílio emergencial não planejado pelo governo.

\section{A questão do financiamento}

Como serão financiados os elevados gastos com o Covid-19? Ao contrário do que está acontecendo na maioria dos países ricos que dispõe de moeda e banco central próprios, ${ }^{5}$ e do que fez a Argentina, ${ }^{6}$ que estão financiando uma parte nunca declarada mais elevada desses gastos com emissão monetária, nossos três países estão fazendo um financiamento ortodoxo através de aumento do endividamento junto ao setor privado. Meu entendimento é que esse foi um erro que o Brasil poderia ter evitado. Com o surgimento da pandemia, foi aprovada no Congresso brasileiro a emenda constitucional 106 denominada "Orçamento de Guerra" que instituiu um regime extraordinário, fiscal, financeiro e de contratações, para atender às necessidades decorrentes do estado de calamidade pública, que autorizou a flexibilização da Lei de Responsabilidade Fiscal, e autorizou a inobservância da "regra de ouro" em matéria orçamentária que determina que as receitas de operações de crédito não podem ser empregadas para financiar despesas correntes. Constou da proposta de emenda a permissão, dada excepcionalmente ao Banco Central, para comprar títulos novos do Tesouro para financiar os gastos com o Covid-19, mas ela não teve apoio do governo e foi rejeitada pelos congressistas. Meu entendimento é que esse foi um erro. Os governos que não adotaram a emissão de moeda para se financiarem perderam autonomia sobre quanto gastar com o Covid-19, enquanto o financiamento junto ao setor privado implicava aumento da dívida pública.

Uma variável explicativa importante para a definição do valor dos gastos de cada país com o Covid-19 foi, provavelmente, a forma de financiamento escolhida: se o Tesouro emitiu títulos e os financiou no setor privado, ou se o financiou através de compra dos títulos pelo Banco Central. Os países que adotaram o financiamento monetário sentiram-se livres em gastar mais porque, não obstante essa decisão pudesse implicar um déficit público elevado, a dívida pública

\footnotetext{
5 The Economist (2020).

6 A Argentina se financiou a partir de remessas de lucros provenientes do Banco Central. Ver https://www.opc.gob.ar/informes/analisis-de-la-ejecucion-presupuestaria-de-la-administracion-nacionaljunio-2020/ página 05 .
} 
líquida, entendida como a dívida do Tesouro menos seus débitos para com o Banco Central, teria permanecido constante.

Até a Crise Financeira Global de 2008 existia um veto à política de emissão de moeda pelos bancos centrais que era partilhado mesmo pelos economistas que, de um lado, viam a oferta de moeda como endógena, e, de outro, negavam a tese monetarista de que o aumento da oferta de moeda seria a causa da aceleração da inflação. Mas após essa crise, os bancos centrais dos países ricos praticaram a "flexibilização quantitativa" (quantitative easing), que implicava compra de títulos do setor privado e títulos novos emitidos pelo Tesouro, configurando-se, neste segundo caso, financiamento monetário. Os objetivos eram aumentar a oferta de dinheiro ou a liquidez do sistema econômico, reduzir as taxas de juros e, assim, incentivar as empresas a investir ou os consumidores a consumir. $\mathrm{O}$ aumento dos investimentos e do consumo não aconteceu, e os países ricos continuam com suas economias quase-estagnadas desde 2008. Houve, porém, uma consequência provavelmente não intencional (a não ser, creio eu, no caso do Japão): uma grande diminuição da dívida pública dos países que emitiram formalmente moeda. A redução da dívida pública dos Estados Unidos foi relativamente pequena, cerca de $12 \%$, e esse pode ser o motivo pelo qual os economistas americanos não prestaram muita atenção ao fato. Já no caso do Japão, cuja dívida era enorme, o aumento da oferta de moeda via flexibilização quantitativa foi igualmente enorme e reduziu em $77 \%$ essa dívida. O objetivo da flexibilização quantitativa não era reduzir a dívida pública, mas no caso do Japão a flexibilização quantitativa foi tão grande que é difícil acreditar que o governo japonês não tenha também considerado esse fato ao praticá-la. O financiamento monetário não implica, objetivamente, aumento da dívida pública, mas não é isso que diz a contabilidade pública "oficial". O fato de o Tesouro e o Banco Central fazerem parte do mesmo aparelho do Estado não foi considerado, porque as regras internacionais de contabilidade pública não o permitem. Como se vê, não apenas os economistas, mas também os contadores públicos gostam de ficções - uma ficção que, neste caso, desencorajaria os gastos públicos "irresponsáveis" mesmo que eles não causassem inflação.

A emissão de moeda não causa inflação; mesmo que acreditássemos na teoria quantitativa da moeda, porque a quantidade de moeda em circulação em uma economia é endógena. Ela não depende do quanto o Estado emite de dinheiro, mas depende de quanto o Estado, as empresas e as famílias gastam e se financiam para 
realizar esse gasto. No caso dos gastos do Covid-19, há duas formas de financiálos: ou o Tesouro vende seus títulos de dívida ao setor privado ou vende ao Banco Central. Nos dois casos, o aumento da quantidade de moeda é o mesmo. Se o gasto financiado por uma ou outra forma não causa um aumento da demanda superior à oferta agregada, ela não causa aceleração da inflação. Foi o caso do quantitative easing e agora é o caso do Covid-19. Neste caso está havendo aumento do gasto público, mas ele apenas compensa parcialmente a diminuição dos investimentos e do consumo do setor privado causados pela pandemia.

Além da oferta de moeda ser endógena e, por isso, acontecer de qualquer maneira quando há aumento do gasto, o aumento da quantidade de moda não causa inflação se não leva o país para a área do pleno emprego. Mas existe um antigo medo das pessoas de que o financiamento monetário do Estado cause inflação. Que, provavelmente, se originou desde os tempos antigos, quando a inflação era chamada não de aumento de preços, mas de aumento descontrolado da quantidade de dinheiro na economia. ${ }^{7}$ Esse mito foi ressuscitado pelo monetarismo. A alegação básica do monetarismo era que, se os bancos centrais controlassem firmemente a oferta de moeda, a inflação seria controlada. Na literatura econômica existe uma identidade, a equação de troca $(\mathrm{MV}=\mathrm{Yp})$, na qual $\mathrm{M}$ é a quantidade de dinheiro, $\mathrm{V}$ é a velocidade da moeda ou o número de vezes que a moeda circula em um ano, Y é a renda nacional e p, a inflação. É uma identidade porque parte da definição da velocidade de circulação da moeda ( $\mathrm{V}=\mathrm{Yp} / \mathrm{M})$.

Os monetaristas, no entanto, transformaram essa identidade em uma teoria a teoria quantitativa - assumindo que a velocidade da moeda é constante e afirmando que o aumento de $\mathrm{M}$ causa o aumento da inflação, p. Aparentemente, essa teoria é verdadeira porque existe uma estreita correlação entre a quantidade de moeda e a inflação, mas, primeiro, V não é constante, a velocidade da moeda é extremamente variável, mudando com o ciclo econômico. ${ }^{8}$ Segundo, não há razão para dizer que é o aumento em $\mathrm{M}$ que causa o aumento em p; faz mais sentido dizer que é o aumento da inflação que exige que a oferta monetária nominal aumente na medida em que a

\footnotetext{
${ }^{7}$ De acordo com o Online Etymological Dictionary, a inflação, no "sentido monetário de 'aumento dos preços' (originalmente por um aumento na quantidade de dinheiro em circulação) foi registrada pela primeira vez em 1938 no inglês americano."

${ }^{8}$ Nos Estados Unidos, na Grande Depressão, a velocidade do estoque de moeda M2 foi de 1,15 vezes; em 1964; subiu para 1,67 vezes; para 1,89 vezes em 1981; em 1997 alcançou um pico de 2,20 vezes em 1997; em seguida caiu para 1.25 vezes em 2018, e para 1,20 em 2020. (Source: FRED, https://fred.stlouisfed.org/series/M2V, baseado no Federal Reserve Bank).
} 
quantidade de moeda existente em uma economia é endógena - é determinada pela dinâmica do próprio sistema econômico. Uma economia nacional precisa de um nível de liquidez ou quantidade de dinheiro proporcional ao seu PIB para funcionar - para permitir que as transações ocorram sem problemas.

Quando, por algum motivo, a inflação aumenta ou acelera, a oferta nominal de moeda precisa aumentar para que a quantidade real de moeda - a liquidez da economia - seja preservada. Para entender isso, ajuda visualizar a liquidez monetária necessária do sistema com a quantidade de óleo lubrificante que permite que a máquina funcione sem problemas, sem atrito. Assim, a quantidade nominal de dinheiro é endógena e, dada a quantidade real necessária de dinheiro, é a inflação que exige que seu aumento permaneça constante em termos reais. Keynes não disse isso literalmente, mas mostrou que a quantidade de dinheiro em uma economia é endógena. Aqui no Brasil, aprendi o caráter endógeno do dinheiro com Ignácio Rangel, que teve essa ideia observando a realidade brasileira do início dos anos 1960. ${ }^{9}$ Entre os pós-keynesianos, Basil Moore, em 1979, mostrou teoricamente a endogeneidade da moeda. ${ }^{10}$

A teoria da inflação inercial, na forma em que foi desenvolvida no Brasil (o país que teve a experiência mais longa e mais radical desse tipo de inflação), mostrou isso definitivamente no artigo de 1984 que definiu mais amplamente essa teoria e que afirma isso no próprio título, "Fatores aceleradores, mantenedores e sancionadores da inflação. ${ }^{11} \mathrm{O}$ fator acelerador da inflação pode ser um choque de oferta ou demanda, mas na maioria dos casos é o excesso de demanda em relação à oferta; a indexação formal e informal dos preços é o fator inercial ou de manutenção, o que torna a inflação resistente às políticas usuais adotadas para controlá-la; e a indexação formal e informal da economia é o fator sancionador que mantém constante a quantidade real de moeda em um ambiente em que a inflação está reduzindo a quantidade nominal de moeda. ${ }^{12}$ Quanto à rejeição empírica do monetarismo, a flexibilização quantitativa demonstrou definitivamente que o monetarismo não faz sentido. Os bancos centrais dos países ricos compraram diretamente do tesouro e do setor privado cerca de US \$ 15 trilhões sem aumentar a taxa de inflação.

\footnotetext{
${ }^{9}$ Ignácio Rangel (1963).

10 Basil J. Moore (1979).

${ }^{11}$ Bresser-Pereira e Yoshiaki Nakano (1984, p. 5-21).

12 É por isso que, em seu artigo básico sobre essa teoria, Bresser e Nakano (1984) chamaram a oferta de moeda de "fator sancionador da inflação".
} 
Pode-se afirmar que os países que emitiram moeda para financiar suas despesas com o Covid-19 tiveram mais liberdade para gastar do que os países que não puderam emitir moeda, como é o caso dos países da Zona do Euro, que não têm moeda própria. Alguns países como Austrália, Canadá, e Japão estão gastando muito (respectivamente 10,1, 9,1 e 6,8\% do PIB), enquanto outros, como Itália e Espanha, estão gastando pouco (respectivamente 1,2, e 2,7\% do PIB). Os países que gastam menos são exatamente os que cometeram o grande erro de criar o euro e perderam a autonomia da política monetária. Vimos isso muito claramente na crise do euro (2010-2015) e parece que estamos vendo isso novamente na crise do Covid-19. A Alemanha, neste estudo, é uma exceção gastando $6 \%$ do PIB, mas sabemos como a conta fiscal do país é gerenciada com extremo rigor visando enormes superávits em conta corrente e uma indústria competitiva. Sabemos, também, quão competente é sua primeira ministra, Angela Merkel.

No caso atual, além de aumentar a liquidez, essa compra deve ter como objetivo não reduzir a dívida pública, como ocorreu com a experiência quantitativa de flexibilização, mas financiar despesas com o Covid-19 sem aumentar essa dívida. Segundo as projeções do FMI, no final deste ano, a dívida pública do mundo rico deverá aumentar de 106 para $122 \%$ do PIB. ${ }^{13}$ Em relação ao Brasil, a previsão geralmente feita é de um aumento de 78 para $95 \%$ do PIB. Em qualquer circunstância, os enormes gastos estatais necessários para compensar a queda das receitas dos Estados significarão grandes déficits fiscais e, se o financiamento monetário não for adotado, um aumento considerável da dívida pública além de, após a crise, anos e anos pagando essa dívida.

O fato de o financiamento monetário do gasto público não causar inflação a não ser que haja excesso de demanda em relação à oferta não significa que os governos possam realizar gastos à vontade. Esse limite nem sempre é claro e não há razão para correr riscos desnecessários. Apenas em circunstâncias especiais como é esta do Covid-19 é razoável que que se use essa forma de financiamento. Os três países aqui analisados não estão se beneficiando dessa possibilidade: a França, porque não têm sua própria moeda; o Brasil e a Argentina, porque têm um medo da inflação, o que neste caso não se justifica.

\footnotetext{
${ }^{13}$ Fonte: https://www.imf.org/en/Publications/WEO/Issues/2020/06/24/WEOUpdateJune2020].
} 


\section{Resultados econômicos}

Vejamos, finalmente, quais foram os resultados desse grande esforço fiscal realizado pelos nossos três países. Na Tabela 1 estão suas três medidas mais importantes: aumento do desemprego, aumento da pobreza, e diminuição do PIB. O aumento do desemprego foi maior no Brasil: a taxa de desocupação da força de trabalho cresceu 2.3 pontos percentuais contra um aumento na Argentina de 1.5 pontos percentuais. Em relação à França há um dado surpreendente: não houve aumento, mas diminuição do desemprego. Ao anunciar, no dia 13 de agosto, a diminuição de $0,7 \%$ do desemprego no segundo trimestre do ano, o INSEE - Institut National de la Statistique et des Études Économiques, responsável pelas estatísticas do país, informou que o resultado era enganador (a trompé l'œil), porque durante os meses de reclusão, muitos desempregados não foram considerados por não estarem à "procura ativa de emprego". ${ }^{14} \mathrm{O}$ INSEE está, porém, ignorando que na França houve incentivos para as empresas não despedirem trabalhadores, enquanto o Brasil e a Argentina falharam nesse ponto. O auxílio emergencial, no Brasil, foi elevado e abrangente demais, mas não houve qualquer política pública protegendo o emprego. Esse mau desempenho no plano do emprego não foi apenas desses dois países latinoamericanos. Segundo estudo da CEPAL (Comissão Econômica para a América Latina e o Caribe) publicado no dia 2 de julho, mais de 2,7 milhões de empresas e 8,5 milhões de postos formais de trabalho devem ser fechados na América Latina e no Caribe nos próximos seis meses, por causa da pandemia do Covid-19. O relatório avalia o impacto e os desafios enfrentados pelas empresas durante a pandemia, informando que mais de um terço do emprego formal e um quarto do PIB da região são gerados em setores fortemente afetados pela atual crise. Do total de companhias que devem fechar devido à crise, 2,6 milhões são microempresas — 1,4 milhão delas estão no setor do comércio e 290 mil no turismo, segmentos especialmente impactados pelas medidas restritivas adotadas pelos governos para impedir a propagação do novo coronavírus.

$\mathrm{O}$ melhor desempenho do Brasil foi em relação à pobreza. Ela diminuiu 0,9\% contra zero na França e um aumento de 11,5\% na Argentina. A diminuição da pobreza no Brasil está diretamente relacionada com o auxílio emergencial que foi generoso e de grande amplitude. Esse auxílio foi de $\mathrm{R} \$ 600,00$ enquanto o benefício da Bolsa Família pode chegar ao máximo de $\mathrm{R} \$ 205,00$ quando na

\footnotetext{
${ }^{14}$ Fonte: https://www.insee.fr/en/statistiques/4642442\#consulter.
} 
família existem cinco beneficiários. E, embora se previssem 50 milhões, está atendendo 66,9 milhões, enquanto o Bolsa Família atende 14,2 milhões de pessoas.

Finalmente, a diminuição do PIB. Os três países estão sofrendo uma pesada diminuição de sua renda, mas o pior desempenho foi o da França, onde a estimativa de queda do PIB neste ano sobe a 12,5 \% contra uma queda de 9,1\% no Brasil e de 9,9\% na Argentina. A queda maior na França é compreensível porque foi o país que gastou menos para neutralizar os efeitos negativos da pandemia, mas o dado contradiz o fato que no segundo trimestre do ano não houve aumento mas uma pequena diminuição do desemprego. A queda prevista do PIB brasileiro em 2020, de $9,1 \%$, é compatível com o grande aumento do desemprego.

\section{Conclusão}

Em síntese, embora o Brasil tenha gastado mais em relação ao PIB do que a França e a Argentina, seus resultados em termos de número de mortes causadas pelo Covid-19 foram muito piores do que os desses países. O pior resultado da França em relação à Argentina decorreu da demora inicial do governo em agir; o pior resultado do Brasil, de o governo federal ter praticado antes uma antipolítica do que uma política de combate ao vírus que foi apenas parcialmente compensada pelas decisões do Congresso e dos governadores e pela existência, desde a transição democrática, de um sistema universal de saúde. Não obstante, o Brasil foi o país que gastou mais com o Covid-19 devido, principalmente, ao amplo e generoso auxílio emergencial adotado pelo Congresso. Foi isto que permitiu um melhor resultado do que o da Argentina em termos de aumento de pobreza; houve mesmo uma pequena diminuição da pobreza. A queda do PIB, porém, foi apenas ligeiramente menor no Brasil do que nos outros dois países.

\section{Referências}

BRESSER-PEREIRA, L. C. A Argentina, o vírus e o presidente. Nueva Sociedad 287, maio-junho, p. 60-67, 2020.

BRESSER-PEREIRA, L. C. YOSHIAKI, N. Accelerating, maintaining, and sanctioning factors of inflation. Brazilian Journal of Political Economy, v. 4, n. 1, p. 5-21, 1984. 
GONZALEZ, L.; BARREIRA, B. Efeitos do auxílio emergencial sobre a renda. Centro de Estudos de Microfinanças e Inclusão Financeira, EAESP/FGV, agosto 2020 .

INSTITUTO NACIONAL DE ESTADÍSTICA Y CENSOS (INDEC). Mercado de trabajo. Tasas e indicadores socioeconómicos (EPH). Trabajo e Ingressos, v. 4, n. 3, Junio 2020.

INTERNATIONAL MONETARY FUND. World Economic Outlook, June 2020a.

INTERNATIONAL MONETARY FUND. Policy Responses to Covid-19. April 2020b.

MOORE, B. J. The endogenous money stocks", Journal of Post Keynesian Economics, v. 2, n. 1, p. 49-70, 1979.

NATANSON, J. A Argentina, o vírus e o presidente. Nueva Sociedad 287, maiojunho, p. 60-67, 2020.

RANGEL, I. M. A Inflação Brasileira. Rio de Janeiro: Tempo Brasileiro, 1963.

RUPRECHT, T. Entrevista: por que o número de mortes por coronavírus está subestimado. Veja Saúde, 03/05/2020.

SACHS, J.; SCHMIDT-TRAUB, G.; KROLL, C.; LAFORTUNE, G.; FULLER, G. Sustainable Development Report 2019. New York: Bertelsmann Stiftung and Sustainable Development Solutions Network (SDSN), 2019.

SACHS, J.; SCHMIDT-TRAUB, G.; KROLL, C.; LAFORTUNE, G.; FULLER, G.; WOELM, F. The Sustainable Development Goals and COVID-19. Sustainable Development Report 2020. Cambridge: Cambridge University Press, 2020.

SOUZA PINTO, A. E. de Taxa de positivo em testes indica que epidemia está subestimada no Brasil. Folha de S. Paulo, 23/6/2020.

THE ECONOMIST. Free money: When government spending knows no limits A new era for economics. The Economist, 25/07/2020. 